\title{
Stability Analysis of R\&D Cooperation in a Supply Chain
}

\author{
Luyun Xu, ${ }^{1}$ Dong Liang, ${ }^{2}$ Zhenjie Duan, ${ }^{2}$ and Xu Xiao ${ }^{2}$ \\ ${ }^{1}$ College of Business Administration, Hunan University, Changsha 410082, China \\ ${ }^{2}$ College of Mathematics and Computer Science, Hunan Normal University, Changsha 410081, China
}

Correspondence should be addressed to Luyun Xu; xuluyun@hnu.edu.cn

Received 18 May 2015; Accepted 13 August 2015

Academic Editor: Leonid Shaikhet

Copyright () 2015 Luyun Xu et al. This is an open access article distributed under the Creative Commons Attribution License, which permits unrestricted use, distribution, and reproduction in any medium, provided the original work is properly cited.

\begin{abstract}
R\&D outsourcing becomes the often-adopted strategy for firms to innovate. However, R\&D cooperation often ends up with failure because of its inherent quality of instability. One of the main reasons for cooperation failure is the opportunistic behavior. As the R\&D contract between firms is inherently incomplete, opportunistic behavior always cannot be avoided in the collaborative process. R\&D cooperation has been divided into horizontal and vertical types. This paper utilizes game theory to study opportunistic behavior in the vertical R\&D cooperation and analyzes the equilibrium of the cooperation. Based on the equilibrium and numerical results, it is found that the vertical R\&D cooperation is inherently unstable, and the downstream firm is more likely to break the agreement. The level of knowledge spillovers and the cost of R\&D efforts have different effects on firms' payoffs. When the level of knowledge spillover is low or the cost of R\&D efforts is high, mechanisms such as punishment for opportunism may be more effective to guarantee the stability of cooperation.
\end{abstract}

\section{Introduction}

In the knowledge economy era, the competition of technical market is increasingly fierce, and firms are forced to accelerate the process of technical innovation. However, it is more difficult for firms to accomplish knowledge creation and technological innovation in isolation [1]. R\&D outsourcing becomes the often-adopted strategy for firms to innovate. R\&D cooperation becomes a common phenomenon, which helps firms in sharing risk and cost, accessing knowledge and technological know-how network, and internalizing the externalities created by knowledge spillovers [2-4]. Despite these advantages, the inherent quality of instability of R\&D cooperation often may not be avoided, and $\mathrm{R} \& \mathrm{D}$ cooperation often ends with failure [5-8]. A main reason for cooperation failure is the opportunistic behavior by one party or the other $[9,10]$. Opportunism appears due to the cooperative and competitive relationship of the two collaborative firms. Opportunism is defined as selfish behavior which means seeking a firm's self-interest with deceit at the expense of its partners [11-13]. As the R\&D contract between firms is inherently incomplete, firms in the cooperation are often not accessible to the detailed information about what the partners are expected to do, and it is impossible for a third party to keep watch on R\&D efforts [14]. Therefore, opportunistic behavior always cannot be avoided in the collaborative process.

Based on the types of collaborative partnership, R\&D cooperation has been divided into horizontal and vertical R\&D cooperation. Many of research works have been done about these two types of R\&D cooperation [15-20]. Although firms may arrange their R\&D inputs to realize the maximization of the total profit of the two firms, opportunism may still prevail in these two types of R\&D cooperation. Such noncooperative behavior may prevent a firm from losing its competitive knowledge. However, it would lead to the instability of the cooperation. Kesteloot and Veugelers study the stability of horizontal R\&D cooperation in a repeated game and emphasize the important role of spillovers [21]. Cabon-Dhersin and Ramani use a noncooperative game to discuss the effect of trust on horizontal R\&D cooperation, and they find that when opportunism cannot be avoided, the nature of firms, the configurations of trust, and the level of spillovers decide whether the horizontal R\&D cooperation is successful or not [14]. Cassiman and Veugelers find that, in vertical cooperation, the effectiveness of strategic protection 
is important to induce cooperation [22]. Lhuillery and Pfister find that vertical $\mathrm{R} \& \mathrm{D}$ cooperation also faces a higher risk of failures [23].

Most of the existing literatures using game theoretical approach have studied the stability of horizontal R\&D cooperation. Our paper uses a game theoretical approach to analyze the stability of the vertical R\&D cooperation. We focus on opportunistic behavior in the vertical $\mathrm{R} \& \mathrm{D}$ cooperation. The results of this paper indicate that the vertical $R \& D$ cooperation is unstable, and the downstream firm is more likely to break the agreement. When building a partnership, firms need to consider the social statue and reputation of its partner and mutual trust between the two firms. This paper also identifies the roles of knowledge spillover and the cost of $R \& D$ effort in the stability of vertical $R \& D$ cooperation. These two factors influence the firms' payoffs in different situations. And they play different roles in the decision process. It is found that when the level of knowledge spillover is low or the cost of R\&D efforts is high, mechanisms such as punishment for opportunism may be more effective.

The rest of this paper is given as follows. Section 2 introduces the model of our paper. Section 3 gives the equilibrium analysis of the game and analyzes the effects of spillover level and R\&D effort cost on stability of the game. Section 4 presents numerical illustration and Section 5 gives the conclusion of this paper.

\section{The Model}

In the part, we present the model in two subsections. Our game model is described in the first subsection. R\&D expenditures and payoffs in different situations are solved in the second subsection.

2.1. Description of Game Model. Studies show that single source brings long-term benefits if used appropriately [24] and one or two suppliers are usually $[25,26]$ enough for a manufacturer. Following Ge et al. [20], we consider cooperative $R \& D$ in a simple supply chain with a final-good manufacturer (denoted as Firm $A$ ) and an input supplier (denoted as Firm $B$ ) in our model.

We assume that Firm $A$ decides its production quantity based on the market demand and then submits its order to Firm $B$. Firm $B$ sells inputs to Firm $A$ in the market. The two firms in the supply chain establish a vertical strategic R\&D collaboration link. The reduction of marginal cost in our study is an R\&D production function following d'Aspremont and Jacquemin [5]. In the vertical $R \& D$ cooperation, firms coordinate their $R \& D$ inputs and then allocate $R \& D$ resources to reduce the production costs. The reduction of marginal production cost comes from a firm's own research. Meanwhile, R\&D efforts of its cooperator also help reducing the firm's cost due to positive spillovers. Let $\beta \in[0,1]$ be the parameter reflecting the spillover level between firms. The spillover levels of the two firms in the vertical R\&D cooperation are assumed to be symmetric. We also assume that the fixed costs of firms are set to be zero. Let $\bar{c}_{i}$ and $\bar{c}_{i}>0$ denote the original marginal cost and let $e_{i}$ denote the R\&D efforts of firm $i$. Therefore, the marginal cost $c_{i}$ after R\&D investment of firm $i$ is written as follows:

$$
c_{i}=\bar{c}_{i}-e_{i}-\beta e_{j}, \quad i, j=A, B, j \neq i .
$$

We assume that R\&D investment is costly. Given a level $e_{i} \in\left[0, \bar{c}_{i}\right)$ of $\mathrm{R} \& \mathrm{D}$ efforts, the cost of efforts is given by $(1 / 2) \gamma e_{i}^{2}$, and $\gamma$ is a technological parameter and satisfies $\gamma>0$, indicating diminishing returns to $\mathrm{R} \& \mathrm{D}$.

In the production market, let us suppose that Firm $B$ produces the inputs and sells them to Firm $A$ at price $P_{s}$, and Firm $A$ uses the inputs to produce final goods. Let us suppose that the inverse demand function in the market is given by $P=a-q$, where $P$ represents the price of a final product and $q$ represents the total production quantity of final goods produced by Firm $A$. At the same time, the order quantity of Firm $A$ is equal to production quantity of final goods. Given an R\&D profile $\left(e_{A}, e_{B}\right)$ of the two firms, the quantity $q$ of final goods and the input price $P_{S}$ of Firm $B$ and the net profits of Firm $A$ and Firm $B,\left(\pi_{A}, \pi_{B}\right)$, can be written as follows:

$$
\begin{aligned}
& \pi_{A}=\left(a-q-\bar{c}_{A}+e_{A}+\beta e_{B}\right) q-P_{S} q-\frac{1}{2} \gamma e_{A}{ }^{2}, \\
& \pi_{B}=\left(P_{S}-\bar{c}_{B}+e_{B}+\beta e_{A}\right) q-\frac{1}{2} \gamma e_{B}{ }^{2} .
\end{aligned}
$$

As the game is dynamic, we can use the backward introduction method. We start with the quantity of final goods. Firm $A$ chooses its output level independently to realize the maximization of its own profit. For any configuration of R\&D efforts $\left(e_{A}, e_{B}\right)$ invested by Firm $A$ and Firm $B$, the optimal condition for the profit maximization of Firm $A$ is given by

$$
\frac{\partial \pi_{A}}{\partial q}=a-2 q-\bar{c}_{A}+e_{A}+\beta e_{B}-P_{S}=0 .
$$

Then the production quantity of the final product can be got by

$$
q=\frac{1}{2}\left(a-\bar{c}_{A}+e_{A}+\beta e_{B}-P_{S}\right) .
$$

Substituting (5) into (3), the net profit function of Firm $B$ can be rewritten as

$$
\begin{aligned}
\pi_{B}= & \frac{1}{2}\left(P_{S}-\bar{c}_{B}+e_{B}+\beta e_{A}\right)\left(a-\bar{c}_{A}+e_{A}+\beta e_{B}-P_{S}\right) \\
& -\frac{1}{2} \gamma e_{B}{ }^{2} .
\end{aligned}
$$

By solving partial derivatives of (6) about $P_{S}$ for profit maximization, the optimal input price can be got as follows:

$$
P_{S}=\frac{1}{2}\left[a-\bar{c}_{A}+\bar{c}_{B}+(1-\beta) e_{A}-(1-\beta) e_{B}\right] .
$$

Then the production quantity of the final product can be obtained as follows:

$$
q=\frac{1}{4}\left[a-\bar{c}_{A}-\bar{c}_{B}+(1+\beta) e_{A}+(1+\beta) e_{B}\right] .
$$


Therefore, the net profits of Firm $A$ and Firm $B$ are gained as

$$
\begin{aligned}
& \pi_{A}=\frac{1}{16}\left[a-c_{A}-c_{B}+(1+\beta)\left(e_{A}+e_{B}\right)\right]^{2}-\frac{1}{2} \gamma e_{A}{ }^{2}, \\
& \pi_{B}=\frac{1}{8}\left[a-c_{A}-c_{B}+(1+\beta)\left(e_{A}+e_{B}\right)\right]^{2}-\frac{1}{2} \gamma e_{B}{ }^{2} .
\end{aligned}
$$

The total profit of the supply chain profit is

$$
\begin{aligned}
\pi_{T}=\pi_{A}+\pi_{B}= & \frac{3}{16}\left[a-c_{A}-c_{B}+(1+\beta)\left(e_{A}+e_{B}\right)\right]^{2} \\
& -\frac{1}{2} \gamma\left(e_{A}{ }^{2}+e_{B}{ }^{2}\right) .
\end{aligned}
$$

2.2. R\&D Expenditures and Payoffs in Different Situations. After establishing the R\&D cooperation, firms choose their levels of R\&D efforts. Each firm has two choices. One is to invest on $\mathrm{R} \& \mathrm{D}$ efforts to maximize the total profit of the two firms, which is treated as reciprocal behavior. Another is to invest on R\&D efforts to maximize a firm's own profit, which is regarded as opportunistic behavior. After that, each firm invests in its R\&D efforts, and this is not observable. With the above discussion, we can now solve for the R\&D efforts and the corresponding net profits in four different situations of vertical R\&D cooperation.

First, Firms $A$ and $B$ both choose reciprocal behavior, and we will define this situation as situation $R R$. In this situation, each firm decides its R\&D efforts by the maximization of the total profit. Then the optimal condition for situation $R R$ is obtained as follows:

$$
\begin{aligned}
& \frac{\partial \pi_{T}}{\partial e_{A}}=\frac{3}{8}(1+\beta)\left[\theta+(1+\beta)\left(e_{A}+e_{B}\right)\right]-\gamma e_{A}=0, \\
& \frac{\partial \pi_{T}}{\partial e_{B}}=\frac{3}{8}(1+\beta)\left[\theta+(1+\beta)\left(e_{A}+e_{B}\right)\right]-\gamma e_{B}=0,
\end{aligned}
$$

where $\theta=a-c_{A}-c_{B}$.

By solving (11), we can, respectively, define the $R \& D$ efforts and net profits of Firm $A$ and Firm $B$ in situation $R R$ as follows:

$$
\begin{gathered}
e_{A}=e_{B}=\frac{3 \theta(1+\beta)}{8 \gamma-6(1+\beta)^{2}}, \\
\pi_{A}=\frac{\gamma \theta^{2}\left[4 \gamma-4.5(1+\beta)^{2}\right]}{\left[8 \gamma-6(1+\beta)^{2}\right]^{2}}, \\
\pi_{B}=\frac{\gamma \theta^{2}\left[8 \gamma-4.5(1+\beta)^{2}\right]}{\left[8 \gamma-6(1+\beta)^{2}\right]^{2}} .
\end{gathered}
$$

Second, Firms $A$ and $B$ both choose opportunistic behavior, defined as situation OO. In this situation, each firm decides its R\&D efforts by the maximization of its own profit. Then the optimal condition for situation $O O$ is expressed by

$$
\begin{aligned}
& \frac{\partial \pi_{A}}{\partial e_{A}}=\frac{1}{8}(1+\beta)\left[\theta+(1+\beta)\left(e_{A}+e_{B}\right)\right]-\gamma e_{A}=0 \\
& \frac{\partial \pi_{B}}{\partial e_{B}}=\frac{1}{4}(1+\beta)\left[\theta+(1+\beta)\left(e_{A}+e_{B}\right)\right]-\gamma e_{B}=0 .
\end{aligned}
$$

And the R\&D efforts and net profits of Firm $A$ and Firm $B$ in situation $O O$ can be separately defined as follows:

$$
\begin{aligned}
& e_{A}=\frac{\theta(1+\beta)}{8 \gamma-3(1+\beta)^{2}}, \\
& e_{B}=\frac{2 \theta(1+\beta)}{8 \gamma-3(1+\beta)^{2}}, \\
& \pi_{A}=\frac{\gamma \theta^{2}\left[4 \gamma-0.5(1+\beta)^{2}\right]}{\left[8 \gamma-3(1+\beta)^{2}\right]^{2}}, \\
& \pi_{B}=\frac{\gamma \theta^{2}\left[8 \gamma-2(1+\beta)^{2}\right]}{\left[8 \gamma-3(1+\beta)^{2}\right]^{2}} .
\end{aligned}
$$

Third, we will define this situation as situation $R O$, where Firm $A$ chooses reciprocal behavior and Firm $B$ chooses opportunistic behavior. At this time, Firm $A$ decides its R\&D efforts for the best interest of the cooperation, while Firm $B$ chooses to cheat. Then the optimal condition for situation $R O$ is written by

$$
\begin{aligned}
& \frac{\partial \pi_{T}}{\partial e_{A}}=\frac{3}{8}(1+\beta)\left[\theta+(1+\beta)\left(e_{A}+e_{B}\right)\right]-\gamma e_{A}=0 \\
& \frac{\partial \pi_{B}}{\partial e_{B}}=\frac{1}{4}(1+\beta)\left[\theta+(1+\beta)\left(e_{A}+e_{B}\right)\right]-\gamma e_{B}=0 .
\end{aligned}
$$

And the R\&D efforts and net profits of Firm $A$ and Firm $B$ in situation $R O$ are severally defined as follows:

$$
\begin{aligned}
& e_{A}=\frac{3 \theta(1+\beta)}{8 \gamma-5(1+\beta)^{2}}, \\
& e_{B}=\frac{2 \theta(1+\beta)}{8 \gamma-5(1+\beta)^{2}}, \\
& \pi_{A}=\frac{\gamma \theta^{2}\left[4 \gamma-4.5(1+\beta)^{2}\right]}{\left[8 \gamma-5(1+\beta)^{2}\right]^{2}}, \\
& \pi_{B}=\frac{\gamma \theta^{2}\left[8 \gamma-2(1+\beta)^{2}\right]}{\left[8 \gamma-5(1+\beta)^{2}\right]^{2}} .
\end{aligned}
$$


TABLE 1: R\&D efforts and payoffs of Firms A and B in different situations.

\begin{tabular}{lcccc}
\hline Situation & $R R$ & $O O$ & $R O$ & $O R$ \\
\hline$e_{A}$ & $\frac{3 \theta(1+\beta)}{8 \gamma-6(1+\beta)^{2}}$ & $\frac{\theta(1+\beta)}{8 \gamma-3(1+\beta)^{2}}$ & $\frac{3 \theta(1+\beta)}{8 \gamma-5(1+\beta)^{2}}$ & $\theta(1+\beta)$ \\
$e_{B}$ & $\frac{3 \theta(1+\beta)}{8 \gamma-6(1+\beta)^{2}}$ & $\frac{2 \theta(1+\beta)}{8 \gamma-3(1+\beta)^{2}}$ & $\frac{2 \theta(1+\beta)}{8 \gamma-5(1+\beta)^{2}}$ & $\frac{3 \theta(1+\beta)}{8 \gamma-4(1+\beta)^{2}}$ \\
$\pi_{A}$ & $\frac{\theta^{2}(4-4.5 L)}{(8-6 L)^{2}}$ & $\frac{\theta^{2}(4-0.5 L)}{(8-3 L)^{2}}$ & $\frac{\theta^{2}(4-4.5 L)}{(8-5 L)^{2}}$ & $\frac{\theta^{2}(4-0.5 L)}{(8-4 L)^{2}}$ \\
$\pi_{B}$ & $\frac{\theta^{2}(8-4.5 L)}{(8-6 L)^{2}}$ & $\frac{\theta^{2}(8-2 L)}{(8-3 L)^{2}}$ & $\frac{\theta^{2}(8-2 L)}{(8-5 L)^{2}}$ & $\frac{\theta^{2}(8-4.5 L)}{(8-4 L)^{2}}$ \\
\hline
\end{tabular}

Similarly, when $A$ chooses opportunistic behavior and Firm $B$ chooses reciprocal behavior, we can define R\&D efforts and net profits in situation $O R$ as follows:

$$
\begin{aligned}
& e_{A}=\frac{\theta(1+\beta)}{8 \gamma-4(1+\beta)^{2}}, \\
& e_{B}=\frac{3 \theta(1+\beta)}{8 \gamma-4(1+\beta)^{2}}, \\
& \pi_{A}=\frac{\gamma \theta^{2}\left[4 \gamma-0.5(1+\beta)^{2}\right]}{\left[8 \gamma-4(1+\beta)^{2}\right]^{2}}, \\
& \pi_{B}=\frac{\gamma \theta^{2}\left[8 \gamma-4.5(1+\beta)^{2}\right]}{\left[8 \gamma-4(1+\beta)^{2}\right]^{2}} .
\end{aligned}
$$

The details in four situations are summarized in Table 1, where $L=(1+\beta)^{2} / \gamma$, and $L$ increases with the spillover level between cooperative firms but decreases with the cost of R\&D efforts. We will assume that $0<L<8 / 9$ to make sure that the $\mathrm{R} \& \mathrm{D}$ investment and production quantity exist.

\section{Equilibrium Analysis}

In this part, we first compare the payoffs of Firm $A$ and Firm $B$ in different statuses and obtain the equilibrium of the game. Second, we, respectively, discuss the effects of spillover level and R\&D cost on profits of four different situations.

3.1. Comparison of Payoffs in Different Status. According to the behavior decision-making and the corresponding profit, the payoff matrix of different $\mathrm{R} \& \mathrm{D}$ investment profiles is given in Table 2. Given the comparison of the profits between different situations, three lemmas have been derived in the following.

Lemma 1. Comparison of payoffs of Firm A in four different situations is as follows:

(1) If Firm A is reciprocal while its partner is opportunistic, Firm A will get a lower profit compared with the profit
TABLE 2: The payoff matrix of different R\&D investment profiles.

\begin{tabular}{lcc}
\hline & $\begin{array}{c}\text { Reciprocal } \\
\text { behavior }\end{array}$ & $\begin{array}{c}\text { Firm } B \\
\text { Opportunistic } \\
\text { behavior }\end{array}$ \\
\hline Firm $A$ & $\left(\pi_{A}^{R R}, \pi_{B}^{R R}\right)$ & $\left(\pi_{A}^{R O}, \pi_{B}^{R O}\right)$ \\
Reciprocal behavior & $\left(\pi_{A}^{\mathrm{OR}}, \pi_{B}^{\mathrm{OR}}\right)$ & $\left(\pi_{A}^{\mathrm{OO}}, \pi_{B}^{\mathrm{OO}}\right)$ \\
\hline
\end{tabular}

yielded by the R\&D cooperation with two reciprocal firms

$$
\pi_{A}^{R R}>\pi_{A}^{R O}
$$

(2) If Firm A is opportunistic while its partner is reciprocal, Firm A will get a higher profit compared with the profit yielded by the R\&D cooperation with two opportunistic firms

$$
\pi_{A}^{\mathrm{OR}}>\pi_{A}^{\mathrm{OO}}
$$

(3) Firm A will get a higher profit from R\&D cooperation with two opportunistic firms than the R\&D cooperation with two reciprocal firms

$$
\pi_{A}^{\mathrm{OO}}>\pi_{A}^{R R}
$$

The particulars of the derivations are presented in the appendix. From the results of Lemma 1, the profit comparison of Firm $A$ in four different situations is given as follows:

$$
\pi_{A}^{O R}>\pi_{A}^{O O}>\pi_{A}^{R R}>\pi_{A}^{R O}
$$

In the vertical R\&D cooperation, for any value of the cost effort $\gamma$ and the spillover level $\beta$, the downstream firm always benefits more from opportunistic behavior. Cheating is an optimal strategy for Firm $A$ in cooperation game.

Lemma 2. Comparison of payoffs of Firm B in four different situations is as follows:

(1) If Firm B is reciprocal while its partner is opportunistic, Firm $B$ will get a lower profit compared with the profit 
yielded by the R\&D cooperation with two reciprocal firms

$$
\pi_{B}^{R R}>\pi_{B}^{O R}
$$

(2) If Firm B is opportunistic while its partner is reciprocal, Firm $B$ will get a higher profit compared with the profit yielded by the R\&D cooperation with two opportunistic firms

$$
\pi_{B}^{R O}>\pi_{B}^{O O}
$$

(3) If Firm B is reciprocal while its partner is opportunistic, Firm $B$ will get a lower profit compared with the profit yielded by the ReD cooperation with two opportunistic firms

$$
\pi_{B}^{\mathrm{OO}}>\pi_{B}^{\mathrm{OR}}
$$

(4) Firm B will get a higher profit from R\&D cooperation with two reciprocal firms than the R\&D cooperation with two opportunistic firms

$$
\pi_{B}^{R R}>\pi_{B}^{O O}
$$

(5) When the inequality $0<L<(80-\sqrt{1216}) / 81$ is satisfied, Firm $B$ will get a higher profit from the R\&D cooperation with only Firm $B$ cheating than the cooperation with two reciprocal firms. When the inequality $(80-\sqrt{1216}) / 81<L<8 / 9$ is satisfied, Firm $B$ will get a lower profit from the R\&D cooperation with only Firm $B$ cheating than the cooperation with two reciprocal firms

$$
\begin{aligned}
\text { When } 0 & <L<\frac{80-\sqrt{1216}}{81}, \\
\text { When } \frac{80-\sqrt{1216}}{81} & <L<\frac{8}{9}, \\
\pi_{B}^{R O}>\pi_{B}^{R R} & >\pi_{B}^{R O} .
\end{aligned}
$$

The particulars of the derivations are also presented in the appendix. From the results of Lemma 2, the profit comparison of Firm $B$ in four different situations is given as follows:

$$
\begin{aligned}
& \text { When } 0<L<\frac{80-\sqrt{1216}}{81}, \\
& \pi_{B}^{R O}>\pi_{B}^{R R}>\pi_{B}^{O O}>\pi_{B}^{O R} \\
& \text { When } \frac{80-\sqrt{1216}}{81}<L<\frac{8}{9}, \\
& \pi_{B}^{R R}>\pi_{B}^{R O}>\pi_{B}^{O O}>\pi_{B}^{O R} .
\end{aligned}
$$

In the vertical R\&D cooperation, the optimal strategy for Firm $B$ is influenced by the R\&D effort $\operatorname{cost} \gamma$ and the spillover level $\beta$. Lower value of $L$ indicates that the cost of R\&D efforts may be high or the spillover level may be low. Upstream Firm $B$ benefits more from opportunistic behavior. Higher value of $L$ indicates that the cost of R\&D efforts may be low or the spillover level may be high. At this time, reciprocal behavior of two firms yields the highest profit to Firm $B$.

Based on the above analysis, we can obtain the equilibrium of the game. At the equilibrium, the optimal strategies for both of the two firms are choosing opportunistic behavior. Therefore, the vertical R\&D cooperation is inherently unstable.

3.2. Effects of Spillover and R\&D Cost on Profits. As mentioned above, the value of $L$ depends on the level of knowledge spillover and the cost of R\&D effort. In this part, we mainly analyze their effects on the profits of Firm $A$ and Firm $B$ in different situations.

Proposition 3. In the vertical R\&D cooperation, the profits of Firm A gained from reciprocal behavior decrease when the level of spillover $\beta$ increases and the cost of R\&D efforts $\gamma$ declines.

Proof. Consider

$$
\begin{aligned}
\frac{\partial \pi_{A}^{R R}}{\partial L}= & \frac{\partial \theta^{2}(4-4.5 L)(8-6 L)^{-2}}{\partial L} \\
= & -4.5 \theta^{2}(8-6 L)^{-2} \\
& +12 \theta^{2}(4-4.5 L)(8-6 L)^{-3} \\
= & \frac{-4.5 \theta^{2}(8-6 L)+12 \theta^{2}(4-4.5 L)}{(8-6 L)^{3}} \\
= & \frac{\theta^{2}(8-27 L)}{(8-6 L)^{3}}<0 .
\end{aligned}
$$

Similarly, it is easy to obtain $\partial \pi_{A}^{R O} / \partial L=\theta^{2}(4-22.5 L) /(8-$ $5 L)^{3}<0$. The values of $\pi_{A}^{R R}$ and $\pi_{A}^{R O}$ decrease with the increase of the value of $L$. As $L=(1+\beta)^{2} / \gamma$, we can learn that when the level of spillover $\beta$ increases and the cost of $R \& D$ efforts $\gamma$ declines, the profits of Firm $A$ gotten from reciprocal behavior decrease.

Proposition 4. In the vertical R\&D cooperation, the profits of Firm A gained from opportunistic behavior increase when the level of spillover $\beta$ rises and the cost of R\&D efforts $\gamma$ declines.

Proof. Consider

$$
\begin{aligned}
\frac{\partial \pi_{A}^{O O}}{\partial L}= & \frac{\partial \theta^{2}(4-0.5 L)(8-3 L)^{-2}}{\partial L} \\
= & -0.5 \theta^{2}(8-3 L)^{-2} \\
& +6 \theta^{2}(4-0.5 L)(8-3 L)^{-3}
\end{aligned}
$$


TABLE 3: The profits of four situations in different levels of spillovers.

\begin{tabular}{lccccccccc}
\hline$\beta$ & $L$ & $\pi_{A}^{R R}$ & $\pi_{A}^{\mathrm{OO}}$ & $\pi_{A}^{R O}$ & $\pi_{A}^{\mathrm{OR}}$ & $\pi_{B}^{R R}$ & $\pi_{B}^{\mathrm{OO}}$ & $\pi_{B}^{R O}$ & $\pi_{B}^{\mathrm{OR}}$ \\
\hline 0.00 & 0.20 & 167.60 & 178.05 & 158.16 & 188.08 & 383.87 & 346.97 & 387.76 \\
0.10 & 0.24 & 169.73 & 183.28 & 157.85 & 196.11 & 402.96 & 355.12 & 407.56 & 349.40 \\
0.20 & 0.29 & 171.84 & 189.31 & 157.09 & 205.57 & 426.05 & 364.48 & 431.29 \\
0.30 & 0.34 & 173.77 & 196.24 & 155.65 & 216.71 & 454.16 & 375.17 & 459.86 & 357.39 \\
0.40 & 0.39 & 175.24 & 204.22 & 153.23 & 229.87 & 488.72 & 387.40 & 494.50 & 376.84 \\
0.50 & 0.45 & 175.77 & 213.41 & 149.34 & 245.51 & 531.77 & 401.38 & 536.86 \\
0.60 & 0.51 & 174.59 & 224.01 & 143.27 & 264.21 & 586.37 & 417.39 & 589.32 \\
0.70 & 0.58 & 170.29 & 236.29 & 133.94 & 286.76 & 657.16 & 435.78 & 655.25 \\
0.80 & 0.65 & 160.27 & 250.58 & 119.61 & 314.23 & 751.69 & 456.99 & 739.71 & 417.96 \\
0.90 & 0.72 & 139.55 & 267.29 & 97.42 & 348.13 & 882.81 & 481.56 & 850.45 & 434.58 \\
1.00 & 0.80 & 97.66 & 286.99 & 62.50 & 390.63 & 1074.22 & 510.20 & 1000.00 & 477.43 \\
\hline
\end{tabular}

$$
\begin{aligned}
& =\frac{-0.5 \theta^{2}(8-3 L)+6 \theta^{2}(4-0.5 L)}{(8-3 L)^{3}} \\
& =\frac{\theta^{2}(20-1.5 L)}{(8-3 L)^{3}}>0 .
\end{aligned}
$$

Similarly, it is easy to obtain $\partial \pi_{A}^{O R} / \partial L=\theta^{2}(28-2 L) /(8-$ $4 L)^{3}>0$. The values of $\pi_{A}^{O O}$ and $\pi_{A}^{O R}$ increase with the value of $L$ growing. As $L=(1+\beta)^{2} / \gamma$, we can learn that when the level of spillover $\beta$ increases and the cost of R\&D efforts $\gamma$ declines, the profits of Firm $A$ gotten from opportunistic behavior rise.

Proposition 5. In the vertical R\&D cooperation, the profits of Firm B in four situations will increase when the level of spillover $\beta$ rises and the cost of R\&D efforts $\gamma$ declines.

Proof. Consider

$$
\begin{aligned}
\frac{\partial \pi_{\mathbf{B}}^{R R}}{\partial L}= & \frac{\partial \theta^{2}(8-4.5 L)(8-6 L)^{-2}}{\partial L} \\
= & -4.5 \theta^{2}(8-6 L)^{-2} \\
& +12 \theta^{2}(8-4.5 L)(8-6 L)^{-3} \\
= & \frac{-4.5 \theta^{2}(8-6 L)+12 \theta^{2}(8-4.5 L)}{(8-3 L)^{3}} \\
= & \frac{\theta^{2}(60-27 L)}{(8-6 L)^{3}}>0 .
\end{aligned}
$$

Similarly, it is easy to obtain $\partial \pi_{B}^{R O} / \partial L=\theta^{2}(64-10 L) /(8-$ $5 L)^{3}>0, \partial \pi_{B}^{O O} / \partial L=\theta^{2}(32-6 L) /(8-3 L)^{3}>0$, and $\partial \pi_{B}^{O R} /$ $\partial L=\theta^{2}(28-16 L) /(8-4 L)^{3}>0$. The values of $\pi_{B}^{R R}, \pi_{B}^{R O}, \pi_{B}^{\mathrm{OO}}$, and $\pi_{B}^{O R}$ go up with the value of $L$ increasing. As $L=$ $(1+\beta)^{2} / \gamma$, we can learn that when the level of spillover $\beta$ increases and the cost of R\&D efforts $\gamma$ declines, the profits of Firm $B$ gotten from the vertical cooperation rise.

\section{Numerical Illustration}

In this section, we use numerical illustration to discuss the profits in four different situations and analyze the effects of the level of knowledge spillover and the cost of R\&D efforts on the stability of the R\&D cooperation.

First, in order to analyze the effects of spillover levels on the two firms' profits in different situations, we assume the basic parameters to be as follows:

$$
\begin{aligned}
a & =100, \\
c_{A} & =30, \\
c_{B} & =20, \\
\gamma & =5 .
\end{aligned}
$$

From Table 3 it can be seen that the profits of Firm $A$ in the four situations satisfy $\pi_{A}^{\mathrm{OR}}>\pi_{A}^{\mathrm{OO}}>\pi_{A}^{R R}>\pi_{A}^{R O}$. As the level of knowledge spillover goes up, the comparison of Firm $A$ 's profits remains unchanged. As for Firm $B$, when the level of knowledge spillover stays at a low level, choosing opportunistic behavior brings more benefits to Firm $B$ in the game. However, as the level of knowledge spillover increases to a certain value, Firm $B$ gets the highest profit from cooperation with two reciprocal firms.

From Figure 1 we learn that the profits of Firm $A$ gotten from reciprocal behavior are lower than the profits gained from opportunistic behavior. The higher the level of spillover, the lower benefits Firm $A$ get from reciprocal behavior in the vertical R\&D cooperation. From Figure 2 we can learn that Firm $B$ will get more benefits from its partner's reciprocal behavior. Therefore, Firm $A$ is more likely to choose opportunistic behavior compared with Firm $B$. The vertical R\&D cooperation faces a higher probability of failure. As Figure 1 shows, when the knowledge spillover stays at a low level, the differences among the profits of Firm $A$ in four situations are small. As the level of knowledge spillover increases, the differences among the profits of Firm $A$ in four situations grow. Therefore, when the level of knowledge spillover is low, 
TABLE 4: The profits of four situations in different levels of R\&D effort costs.

\begin{tabular}{lccccccccc}
\hline$\gamma$ & $L$ & $\pi_{A}^{R R}$ & $\pi_{A}^{\mathrm{OO}}$ & $\pi_{A}^{R O}$ & $\pi_{A}^{\mathrm{OR}}$ & $\pi_{B}^{R R}$ & $\pi_{B}^{\mathrm{OO}}$ & $\pi_{B}^{R O}$ & $\pi_{B}^{\mathrm{OR}}$ \\
\hline 3.00 & 0.75 & 127.55 & 274.10 & 86.51 & 362.50 & 943.88 & 491.49 & 899.65 & 462.50 \\
3.50 & 0.64 & 161.27 & 249.48 & 120.85 & 312.07 & 743.91 & 455.36 & 732.90 & 433.26 \\
4.00 & 0.56 & 171.66 & 233.31 & 136.45 & 281.19 & 639.15 & 431.33 & 638.70 & 413.52 \\
4.50 & 0.50 & 175.00 & 221.89 & 144.63 & 260.42 & 575.00 & 414.20 & 578.51 & 399.31 \\
5.00 & 0.45 & 175.77 & 213.41 & 149.34 & 245.51 & 531.77 & 401.38 & 536.86 & 388.59 \\
5.50 & 0.41 & 175.52 & 206.86 & 152.23 & 234.31 & 500.71 & 391.42 & 506.38 & 380.23 \\
6.00 & 0.38 & 174.86 & 201.65 & 154.10 & 225.59 & 477.32 & 383.47 & 483.13 & 373.52 \\
6.50 & 0.35 & 174.04 & 197.41 & 155.35 & 218.61 & 459.08 & 376.97 & 464.83 & 368.02 \\
7.00 & 0.32 & 173.18 & 193.90 & 156.21 & 212.91 & 444.46 & 371.56 & 450.05 & 363.43 \\
7.50 & 0.30 & 172.35 & 190.93 & 156.80 & 208.15 & 432.49 & 366.99 & 437.87 & 359.54 \\
\hline
\end{tabular}

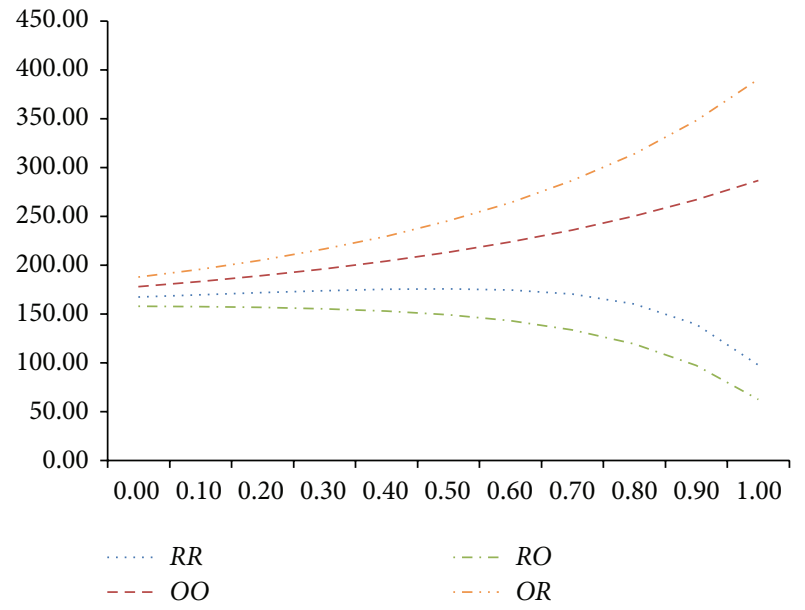

Figure 1: The profits of Firm $A$ in different levels of spillovers.

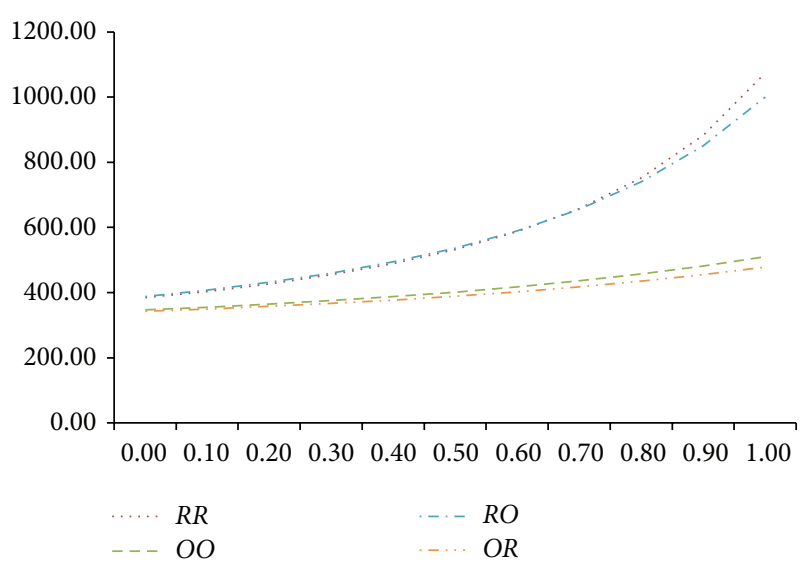

Figure 2: The profits of Firm $B$ in different levels of spillovers.

mechanisms such as punishment for opportunism may be more effective to guarantee the stability of cooperation.
Second, in order to analyze the effects of R\&D effort cost on the two firms' profits in different situations, we assume the basic parameters to be as follows:

$$
\begin{aligned}
a & =100, \\
c_{A} & =30, \\
c_{B} & =20, \\
\beta & =0.5 .
\end{aligned}
$$

From Table 4 it can also be seen that the profits of Firm $A$ in the four situations satisfy $\pi_{A}^{O R}>\pi_{A}^{O O}>\pi_{A}^{R R}>\pi_{A}^{R O}$. As the cost of R\&D efforts goes up, the comparison of the Firm $A$ 's profits remains unchanged. As for Firm $B$, when the cost of R\&D efforts stays at a low level, choosing reciprocal behavior brings more benefits to Firm $B$ in the game. However, as the cost of R\&D efforts increases to a certain value, Firm $B$ gets higher profits from cooperation with two reciprocal firms.

From Figure 1 we learn that the profits of Firm $A$ gotten from reciprocal behavior are lower than those from opportunistic behavior. But when the cost of R\&D efforts increases, the profits of Firm $A$ gotten from reciprocal behavior grow. From Figure 4 we can learn that Firm $B$ will get more benefits from its partner's reciprocal behavior. But its profits decrease with the cost rising. Figures 3 and 4 also indicate that Firm $A$ is more likely to choose opportunistic behavior compared with Firm $B$. Moreover, when the cost of R\&D efforts stays at a high level, the differences among the profits of Firm $A$ in four situations are small. Therefore, when the cost of R\&D efforts is high, mechanisms such as punishment for opportunism may be more effective to guarantee the stability of cooperation.

\section{Conclusion}

As the R\&D contract between firms is inherently incomplete, the opportunistic behavior could not be avoided, which makes the $R \& D$ cooperation unstable. Compared with the game theoretical based literature on the stability of $R \& D$ 


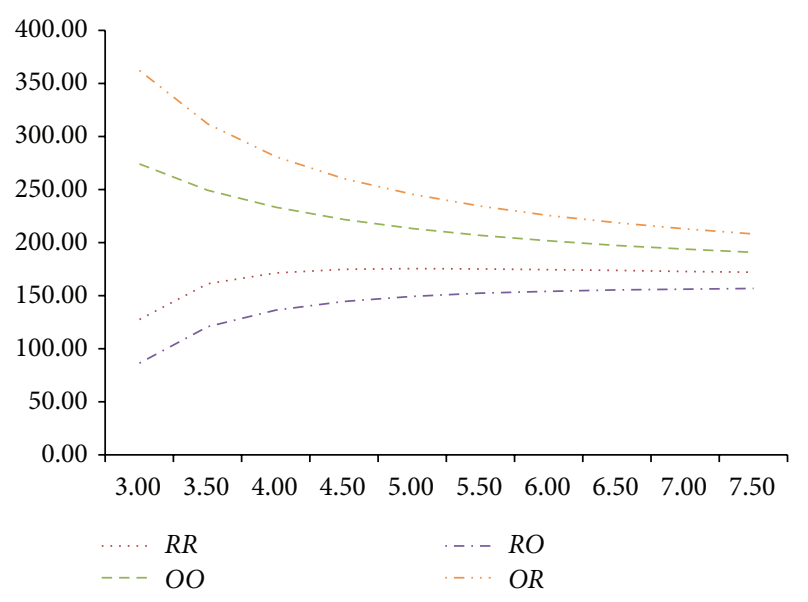

Figure 3: The profits of Firm $A$ in different levels of R\&D effort costs.

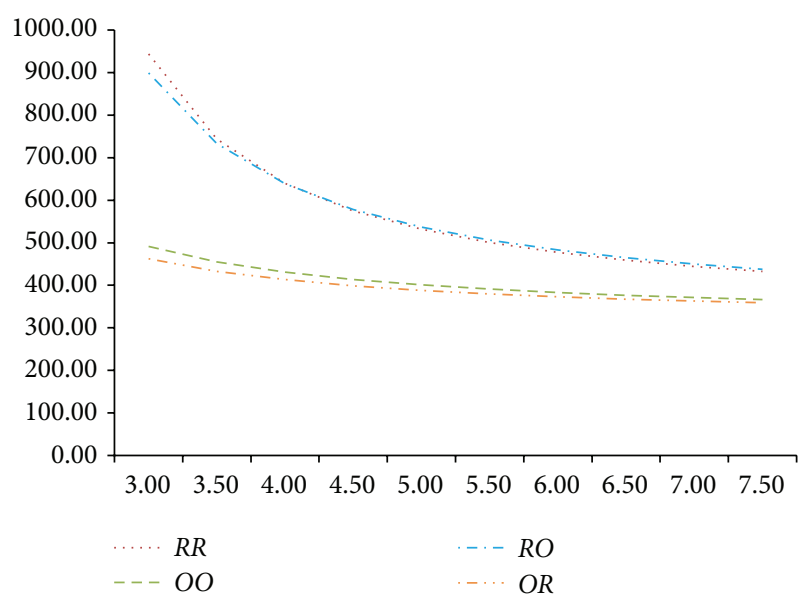

FIGURE 4: The profits of Firm $B$ in different levels of R\&D effort costs.

cooperation, we study the stability of vertical R\&D cooperation. In this paper, we have provided a game model with two firms in the vertical $R \& D$ cooperation to discuss the stability of the cooperation. Two firms first build a partnership and then coordinate their decisions of R\&D efforts. However, due to the cooperative and competitive relationship between the two collaborative firms, opportunism cannot be avoided, which makes the vertical R\&D cooperation fail. We first analyze the profits of Firm $A$ and Firm $B$ in four different situations and then, respectively, compare the values of payoffs of Firm $A$ and Firm $B$. Finally we discuss the effects of spillover level and R\&D cost on profits of four different situations, and numerical illustration is presented.

Our results suggest that the vertical $\mathrm{R} \& \mathrm{D}$ cooperation is inherently unstable, and the downstream firm is more likely to break the agreement. When building a partnership, firms need to consider the social statue and reputation of its partner and mutual trust between the two firms. This paper also identifies the role of knowledge spillovers and the cost of R\&D efforts in the stability of vertical R\&D cooperation. Knowledge flow and R\&D cost influence the firms' payoffs in different situations. And they play different roles in the decision process. We learn that when the level of knowledge spillover is low or the cost of R\&D efforts is high, mechanisms such as punishment for opportunism may be more effective.

These results may provide a theoretical basis for the operation of vertical R\&D cooperation. This paper also raises some questions for future research. First, we note that our analysis concentrates on a simple supply chain with two firms involved. In future work we hope to explore the stability of vertical R\&D cooperation in a more general setting. Second, empirical work can be done to better analyze the opportunism problem in the vertical R\&D cooperation. Third, other factors such as punishment and trust in the stable R\&D cooperation can be considered in future studies.

\section{Appendix}

(1) Derivation of the Comparison of $\pi_{A}^{\mathrm{OO}}$ and $\pi_{A}^{R R}$. Consider

$$
\begin{aligned}
\pi_{A}^{O O}-\pi_{A}^{R R}=\frac{\theta^{2}(4-0.5 L)}{(8-3 L)^{2}}-\frac{\theta^{2}(4-4.5 L)}{(8-6 L)^{2}} \\
=\frac{\theta^{2}}{(8-3 L)^{2}(8-6 L)^{2}}\left[(4-0.5 L)(8-6 L)^{2}\right. \\
\left.-(4-4.5 L)(8-3 L)^{2}\right] \\
=\frac{\theta^{2} L}{(8-3 L)^{2}(8-6 L)^{2}}\left(22.5 L^{2}-60 L+64\right)>0 .
\end{aligned}
$$

Therefore, we can get $\pi_{A}^{\mathrm{OO}}>\pi_{A}^{R R}$.

(2) Derivation of the Comparison of $\pi_{B}^{\mathrm{OO}}$ and $\pi_{B}^{\mathrm{OR}}$. Consider

$$
\begin{aligned}
\pi_{B}^{O O} & -\pi_{B}^{O R}=\frac{\theta^{2}(8-2 L)}{(8-3 L)^{2}}-\frac{\theta^{2}(8-4.5 L)}{(8-4 L)^{2}} \\
& =\frac{\theta^{2}}{(8-3 L)^{2}(8-4 L)^{2}}\left[(8-2 L)(8-4 L)^{2}\right. \\
& \left.-(8-4.5 L)(8-3 L)^{2}\right] \\
& =\frac{\theta^{2}}{(8-3 L)^{2}(8-4 L)^{2}}\left(8.5 L^{2}-32 L+32\right)>0 .
\end{aligned}
$$

Therefore, we can get $\pi_{B}^{\mathrm{OO}}>\pi_{B}^{\mathrm{OR}}$.

(3) Derivation of the Comparison of $\pi_{B}^{R R}$ and $\pi_{B}^{O O}$. Consider

$$
\begin{aligned}
\pi_{B}^{R R} & -\pi_{B}^{\mathrm{OO}}=\frac{\theta^{2}(8-4.5 L)}{(8-6 L)^{2}}-\frac{\theta^{2}(8-2 L)}{(8-3 L)^{2}} \\
& =\frac{\theta^{2}}{(8-3 L)^{2}(8-6 L)^{2}}\left[(8-4.5 L)(8-3 L)^{2}\right. \\
& \left.-(8-2 L)(8-6 L)^{2}\right] \\
& =\frac{\theta^{2} L}{(8-3 L)^{2}(8-6 L)^{2}}\left(31.5 L^{2}-192 L+224\right) .
\end{aligned}
$$


The intersections of the quadratic function $y=31.5 x^{2}-$ $192 x+224$ with the $x$-axis are, respectively, ((192 $\sqrt{8640}) / 63,0)$ and $((192+\sqrt{8640}) / 63,0)$. As $0<L<8 / 9$, therefore, we can get $\pi_{B}^{R R}>\pi_{B}^{\mathrm{OO}}$.

(4) Derivation of the Comparison of $\pi_{B}^{R R}$ and $\pi_{B}^{R O}$. Consider

$$
\begin{aligned}
\pi_{B}^{R R} & -\pi_{B}^{R O}=\frac{\theta^{2}(8-4.5 L)}{(8-6 L)^{2}}-\frac{\theta^{2}(8-2 L)}{(8-5 L)^{2}} \\
& =\frac{\theta^{2}}{(8-6 L)^{2}(8-5 L)^{2}}\left[(8-4.5 L)(8-5 L)^{2}\right. \\
& \left.-(8-2 L)(8-6 L)^{2}\right] \\
& =\frac{\theta^{2} L}{(8-3 L)^{2}(8-6 L)^{2}}\left(-40.5 L^{2}+80 L-32\right) .
\end{aligned}
$$

The intersections of the quadratic function $y=-40.5 L^{2}+$ $80 L-32$ with the $x$-axis are, respectively, $((80-\sqrt{1216}) / 81,0)$ and $((80+\sqrt{1216}) / 81,0)$. As $0<L<8 / 9$, therefore, when $(80-\sqrt{1216}) / 81<L<8 / 9$, we can get $\pi_{B}^{R R}>\pi_{B}^{R O}$, and, when $0<L<(80-\sqrt{1216}) / 81$, we can get $\pi_{B}^{R R}<\pi_{B}^{R O}$.

\section{Conflict of Interests}

The authors declare that there is no conflict of interests regarding the publication of this paper.

\section{Acknowledgments}

This work is supported by the National Science Foundation of China (no. 61502167), the Hunan Provincial Education Department Scientific Research Fund of China (no. 15C0825), Hunan Provincial Science and Technology Program Project of China (no. 2015JC3066), Scientific Research Foundation for Ph.D. Hunan Normal University (no. Math 120641), and Youth Scientific Research Fund of Hunan Normal University (no. 11301).

\section{References}

[1] T. Roediger-Schluga and M. J. Barber, "R\&D collaboration networks in the European Framework Programmes: data processing, network construction and selected results," International Journal of Foresight and Innovation Policy, vol. 4, no. 3-4, pp. 321-347, 2008.

[2] M. Tripsas, S. Schrader, and M. Sobrero, "Discouraging opportunistic behavior in collaborative R \& D: a new role for government," Research Policy, vol. 24, no. 3, pp. 367-389, 1995.

[3] J. E. Oxley and R. C. Sampson, "The scope and governance of international R\&D alliances," Strategic Management Journal, vol. 25, no. 8-9, pp. 723-749, 2004.

[4] V. Mukherjee and S. V. Ramani, "R\&D cooperation in emerging industries, asymmetric innovative capabilities and rationale for technology parks," Theory and Decision, vol. 71, no. 3, pp. 373394, 2011.
[5] C. d'Aspremont and A. Jacquemin, "Cooperative and noncooperative R\&D in duopoly with spillovers," The American Economic Review, vol. 78, no. 5, pp. 1133-1137, 1988.

[6] S. E. Phelan, R. J. Arend, and D. A. Seale, "Using an iterated prisoner's dilemma with exit option to study alliance behavior: results of a tournament and simulation," Computational \& Mathematical Organization Theory, vol. 11, no. 4, pp. 339-356, 2005.

[7] S. H. Park and M. V. Russo, "When competition eclipses cooperation: an event history analysis of joint venture failure," Management Science, vol. 42, no. 6, pp. 875-890, 1996.

[8] M. J. Kelly, J.-L. Schaan, and H. Joncas, "Managing alliance relationships: key challenges in the early stages of collaboration," $R$ \& D Management, vol. 32, no. 1, pp. 11-22, 2002.

[9] J. Walter, F. W. Kellermanns, and C. Lechner, "Decision making within and between organizations: rationality, politics, and alliance performance," Journal of Management, vol. 38, no. 5, pp. 1582-1610, 2012.

[10] T. K. Das and B.-S. Teng, "Between trust and control: developing confidence in partner cooperation in alliances," Academy of Management Review, vol. 23, no. 3, pp. 491-512, 1998.

[11] K. H. Wathne and J. B. Heide, "Opportunism in interfirm relationships: forms, outcomes, and solutions," Journal of Marketing, vol. 64 , no. 4 , pp. $36-51,2000$.

[12] Y. Luo, "Opportunism in inter-firm exchanges in emerging markets," Management and Organization Review, vol. 2, no. 1, pp. 121-147, 2006.

[13] T. K. Das and N. Rahman, "Determinants of partner opportunism in strategic alliances: a conceptual framework," Journal of Business and Psychology, vol. 25, no. 1, pp. 55-74, 2010.

[14] M.-L. Cabon-Dhersin and S. V. Ramani, "Does trust matter for $\mathrm{R} \& \mathrm{D}$ cooperation? A game theoretic examination," Theory and Decision, vol. 57, no. 2, pp. 143-180, 2004.

[15] A. Ishii, "Cooperative R\&D between vertically related firms with spillovers," International Journal of Industrial Organization, vol. 22, no. 8-9, pp. 1213-1235, 2004.

[16] G. Atallah, "Defecting from R\&D cooperation," Australian Economic Papers, vol. 45, no. 3, pp. 204-226, 2006.

[17] A. Stepanova and A. Tesoriere, "R\&D with spillovers: monopoly versus noncooperative and cooperative duopoly," The Manchester School, vol. 79, no. 1, pp. 125-144, 2011.

[18] C. Burr, M. Knauff, and A. Stepanova, "On the prisoner's dilemma in R\&D with input spillovers and incentives for R\&D cooperation," Mathematical Social Sciences, vol. 66, no. 3, pp. 254261, 2013.

[19] T. Shibata, "Market structure and R\&D investment spillovers," Economic Modelling, vol. 43, pp. 321-329, 2014.

[20] Z. Ge, Q. Hu, and Y. Xia, "Firms' R\&D cooperation behavior in a supply Chain," Production and Operations Management, vol. 23, no. 4, pp. 599-609, 2014.

[21] K. Kesteloot and R. Veugelers, "Stable R\&D cooperation with spillovers," Journal of Economics \& Management Strategy, vol. 4, no. 4, pp. 651-672, 1995.

[22] B. Cassiman and R. Veugelers, "R\&D cooperation and spillovers: some empirical evidence from Belgium," The American Economic Review, vol. 92, no. 4, pp. 1169-1184, 2002.

[23] S. Lhuillery and E. Pfister, "R\&D cooperation and failures in innovation projects: empirical evidence from French CIS data," Research Policy, vol. 38, no. 1, pp. 45-57, 2009. 
[24] R. Newman, "Single source qualification," Journal of Purchasing and Materials Management, vol. 24, no. 2, pp. 10-17, 1988.

[25] W. Presutti, "The single source issue: US and Japanese sourcing strategies," Journal of Supply Chain Management, vol. 28, no. 1, pp. 2-9, 1992.

[26] J. Dyer and W. Ouchi, "Japanese-style partnerships: giving companies a competitive edge," Sloan Management Review, vol. 35, no. 1, pp. 51-63, 1993. 


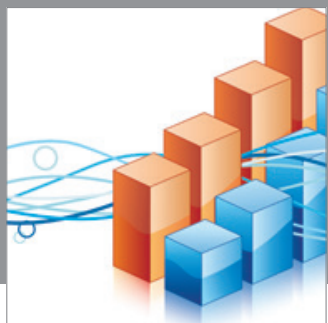

Advances in

Operations Research

mansans

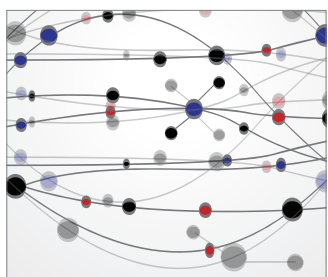

The Scientific World Journal
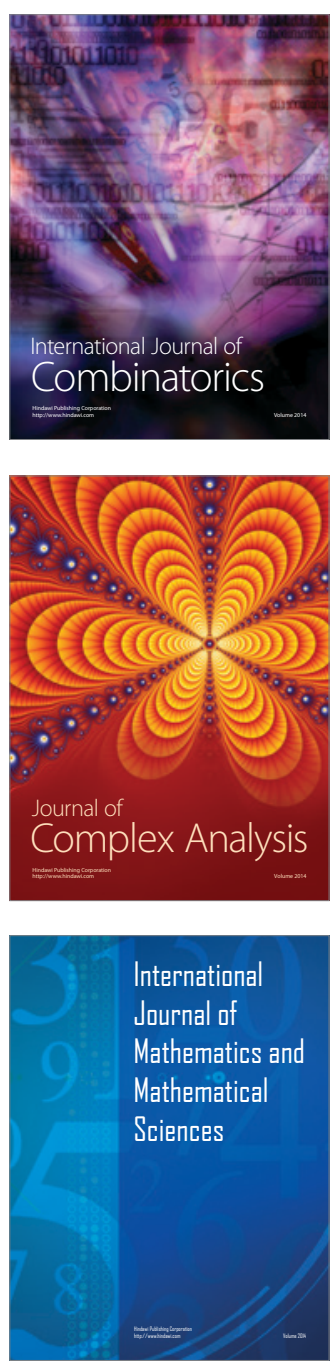
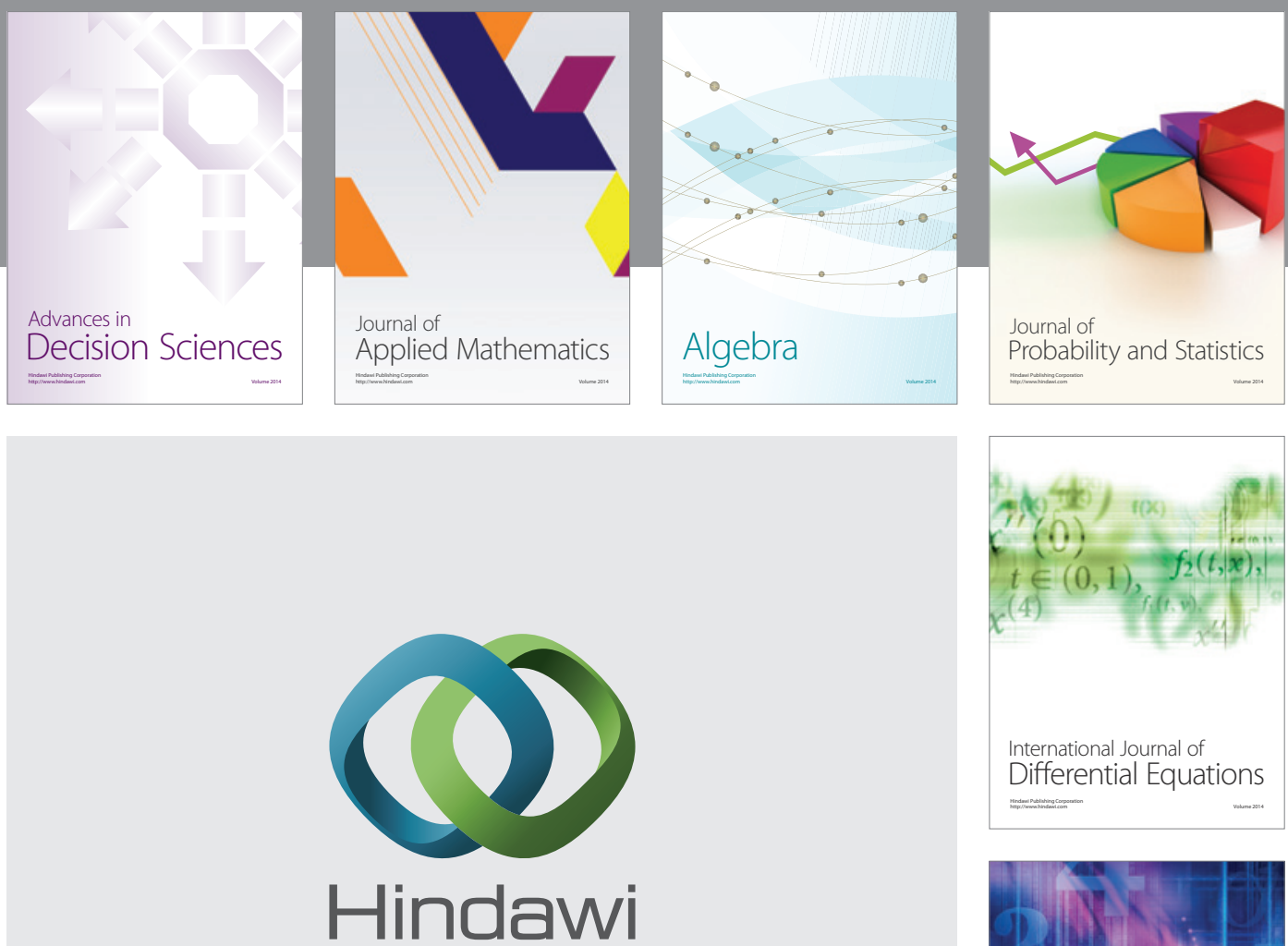

Submit your manuscripts at http://www.hindawi.com
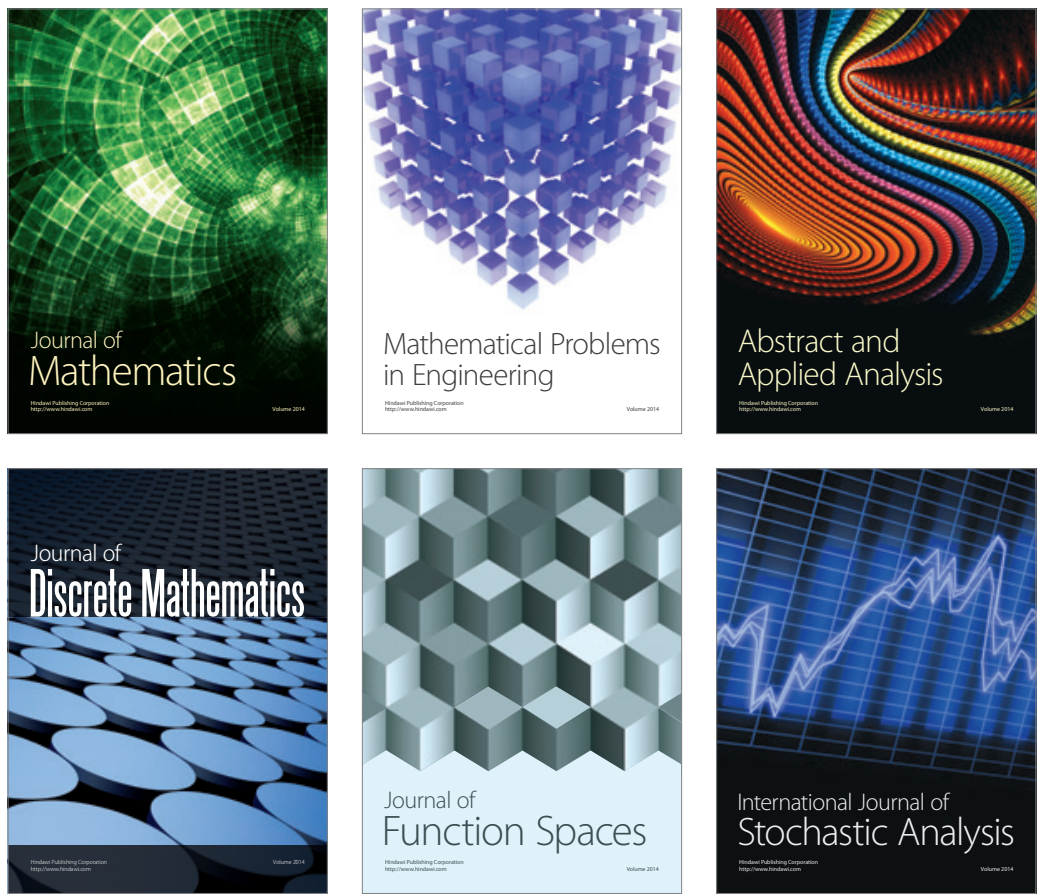

Journal of

Function Spaces

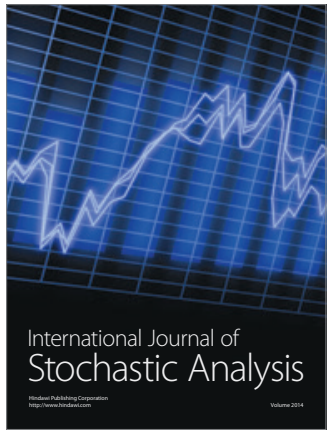

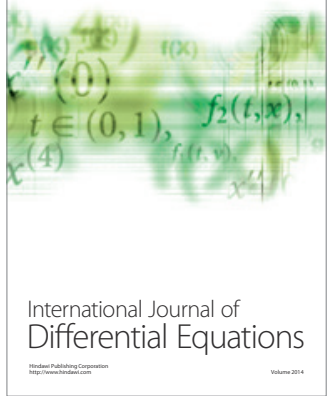
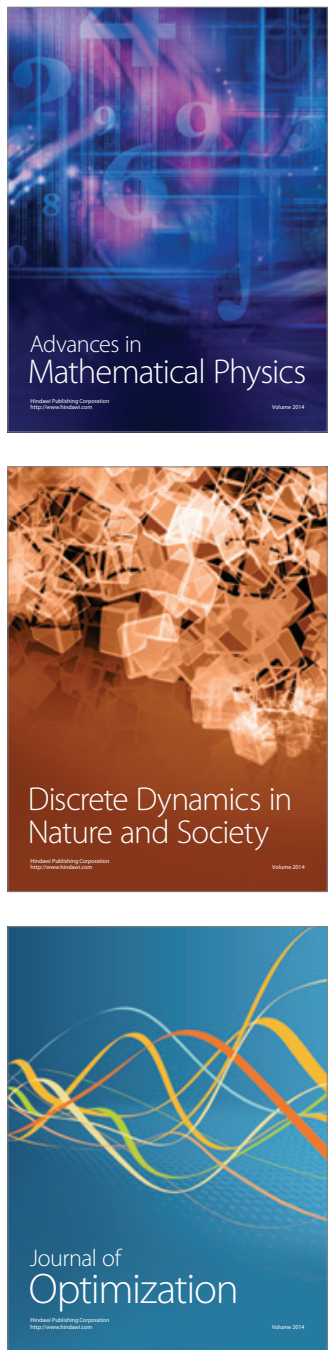